admits, that could be "forty to fifty years away".

Safety will be the main issue at the conference, but the Italian commitment to the fast breeder reactor will also be in question. Italy owns a one-third share in Europe's - and the free world's largest such reactor, the 1,300 MW Superphénix (at Creys-Malville on the French Rhône river), and is also party to a Europe-wide agreement on fast reactor research and development. But the Italian Communist Party (a party of Eurocommunists who distance themselves from Moscow, unlike their French equivalents) has set itself firmly against fast reactors. The Communists are by far the strongest of Italy's left-wing groups, and Colombo is "sorry" that Italian withdrawal from fast-breeder research now seems "likely", although continued participation in Superphénix is ensured (for the electricity it provides Italy). The most immediate impact of withdrawal from research would be the end of the so-called PEC $120 \mathrm{MW}$ (thermal power) experimental fast breeder, designed to study fuel safety, which is now 70 per cent complete on a site midway between Bologna and Florence.

Craxi's conference to "decide" on even this small amount of nuclear power and nuclear research has already begun in one

sense: the industry ministry in Rome has sent questionnaires to 150 environmental groups, nuclear power and other institutions, asking for their forecasts of future electricity demand and supply in Italy, their estimates of environmental damage and risk, and for proposals for an institutional framework for managing Italian energy and any accidents that might arise.

The conference proper will consist of analysis of the replies, reports by invited experts from Italy and the rest of the world and most critically a closing assessment by the government.

Then, an interparliamentary commission will attempt to reach conclusions, but as Colombo predicts, the short conference is likely to leave a very divided field. An assessment of likely votes is as likely to sway politicians as an assessment of technical arguments, and for the Italian nuclear power lobby a public "bella figura" at the conference must be essential.

Meanwhile, however, the spring date approaches when Craxi (a socialist) has promised to hand over the premiership to his Christian Democrat colleagues. $\mathrm{He}$ has refused to do this once before, and many think the same thing may happen again, this time precipitating a general election. That could mean Italy's energy future being decided in the white heat of Italian politics.

Robert Walgate

\title{
Landsat remote sensing project short of funds for satellites
}

\section{Washington}

As a result of a delay in 1987 budget negotiations between Congress and the National Oceanic and Atmospheric Administration (NOAA), work on the two newest Land Remote Sensing Satellites (Landsats 6 and 7) has ground to a halt.

The Earth Observation Satellite Company EOSAT, dependent upon a NOAA subsidy to construct the new satellites, has been forced to terminate Landsat development subcontracts. These contracts were held by the Santa Barbara Research Center of Hughes Aircraft Company and General Electric's RCA Astro-Space Division, among others. Termination of the subcontracts will mean layoffs of up to approximately 200 scientists and technicians for each major contractor, and the loss of 17 marketing support personnel for EOSAT. Although the two currently operating Landsats 4 and 5 will not be immediately affected, a continued lack of funds could drive EOSAT into a worse predicament.

For the past five years, NOAA has been a favourite target of Reagan administration budget cuts, struggling each year to get funding. EOSAT has been prone to the vagaries of the forces influencing the NOAA budget since it was formed to commercialize the Landsats. In 1985, when EOSAT took over the Landsats, Congress decided that EOSAT would receive $\$ 250$ million in start-up funds, to carry EOSAT through the deployment of Landsats 6 and 7. So far, each year EOSAT's subsidy has been deleted from the NOAA budget by the Office of Management and Budget (OMB), only to be put back in by Congress.

For 1987 , EOSAT was scheduled to receive $\$ 87$ million, but $\mathrm{OMB}$ did not approve NOAA's budget. Congress then approved the appropriation of $\$ 27.5 \mathrm{mil}$ lion of new money for EOSAT, but demanded that NOAA provide a detailed plan for the use of the funds. The request for a new plan was prompted by delays in the Shuttle programme since the Challenger accident left the Landsats with no launch vehicle.

The current, unapproved NOAA plan calls for a $\$ 209.2$ million total subsidy, down from the original $\$ 250$ million, for the development of only one satellite instead of two. Launch is proposed for 1989 using a Titan 2 missile. This means a budget in 1987 of $\$ 62.5$ million. EOSAT says it requires a minimum of $\$ 69.5$ millon in 1987, and is still pushing for plans for two new satellites.

\section{NASA mosquito watch threatened}

\section{Washington}

Predicting malaria outbreaks from space may be possible using a model being developed by the National Aeronautics and Space Administration (NASA). The model will use remote-sensing images taken by Land Remote Sensing Satellites (Landsats) of malaria-prone regions to forecast when and where outbreaks are likely to occur. But the budgetary problems that have recently befallen the Earth Observation Satellite company (EOSAT), Landsat's owner, may mean that projects like the malaria watch will have trouble getting off the ground.

If money problems can be solved, the first phase in the development of the malaria model will take place this summer in the rice fields of Northern California. A local species of mosquito is closely related to the ones that spread malaria elsewhere, although California's control measures have rendered the state virtually free of the disease. According to project chief Paul Sebesta, researchers at the NASA Ames Research Center will be collecting "ground truth" data to work out the relationship between the satellite images of ground reflectance patterns and the variables that influence the proliferation of malariabearing mosquitoes. Such ground variables include surface water distribution, rainfall patterns, drainage, vegetation type and temperature. Once these relationships are established, it will be possible to predict both the extent of the mosquito population and how long it will thrive.

The second field trial of the new technique will begin in 1988 in the southwestern oceanic plain of Mexico, near Tapachula, a site with a large malarial mosquito population. The Mexican location was selected during a workshop between NASA scientists and world health officials held early last year at the Uniformed Services Medical Center in Bethesda, Maryland. Criteria for choosing a site were that it should have only one species of mosquito serving as the malaria vector, be politically stable and easily accessible. Costa Rica, Turkey, Pakistan and China were also considered, and they are likely to top the list for future trials. If successful, the model will be turned over to national and international malaria control authorities. Carol Ezzell

Congress, EOSAT, and NOAA are still trying to reach a compromise. Once an agreement has been settled, however, EOSAT will have to renegotiate the contracts with its subcontractors, a task that could set the project for the new Landsats back by nearly two months. Meanwhile, EOSAT, Landsat and the fate of any projects dependent upon Landsat data are caught in budgetary limbo. Carol Ezzell 